\title{
The Effects of a Resilience Enhancing Nursing Program on Depression among Pregnant Teenagers
}

\author{
Umaporn KUASIT ${ }^{1}$, Sopen CHUNUAN ${ }^{1, *}$, \\ Urai HATTHAKIT ${ }^{1}$ and Linda F. C. BULLOCK ${ }^{2}$ \\ ${ }^{1}$ Faculty of Nursing, Prince of Songkla University, Songkhla 90110, Thailand \\ ${ }^{4}$ School of Nursing, University of Virginia, USA
}

("Corresponding author's e-mail: sophen.c@psu.ac.th)

Received: 4 March 2017, Revised: 22 September 2018, Accepted: 20 October 2018

\begin{abstract}
The purposes of this study were to evaluate the effects of the resilience enhancing nursing program (RENP) on resilience and depression among pregnant teenagers who received this program. A quasi experimental was conducted with 130 pregnant Thai women. Final analysis included 130 participants (Intervention $\mathrm{n}=64$ and control group $\mathrm{n}=66$ ). The RENP was delivered in three steps including; Step 1, establishing trusting relationships; Step 2, improving the resilience, and Step 3, monitoring and encouraging the resilience practice. The research instruments consisted of a demographic data questionnaire, and resilience and depressive program instruments, including a handbook and self-report. Research data were analyzed and displayed, providing percentage, mean, standard deviation, chi-square, independent t-test, paired t-test, and the repeated measures ANOVA.

The findings showed a significant difference in depression by time alone $(p=0.001)$. However, there was no significant difference by group alone in depression $(p=0.969)$. This study revealed mean score on depression in the experimental group was not significantly lower than before entering the program at week 4 and week $8(p=0.870, p=0.428)$. However, resilience showed difference in score over time between the experimental group and control group. There was a significant difference in resilience score by time alone $(\mathrm{F}=10.523, p<0.001)$.

The results can contribute to guiding nurses to enhance decrease in depression in pregnant teenagers in the earlier first trimester in antenatal care units. Nurse or nurse midwife should be concerned about the potential for early detection in the prenatal period and provide appropriate interventions to teenage mothers in the postnatal period.
\end{abstract}

Keyword: Pregnant Teenager, Resilience, Healing Presence, Depression

\section{Introduction}

In the current time, teenage pregnancy is a significant problem and a social concern. The increased teenage pregnancy rate has increased costs under the national health plan by at least $10 \%$ [1]. Resilience can help a pregnant teenager prevent adversities from crisis situations, as well as overcome the damaging effects of adversity. The promotion of personal capability for a resilience epistemology is needed, in which adversity is culturally specific and appeals to collective responsibility [2]. The negative consequences impacting a teenage mother include a poor obstetric outcome, depression, and education and socioeconomic risks, such as reduced employment opportunities [3-6].

Depression is a significant mental disorder that demonstrates through depressed moods and poor emotional levels; depression always comes with symptoms of anxiety in general [7]. Moreover, pregnancy may lead to suicide attempts [8]. Therefore, this continuing high rate has led to increased risks 
http://wjst.wu.ac.th

and complications of pregnancy outcomes in this group [9,10]. Resilience can increasingly help pregnant teenagers to overcome adversities from crisis situations, such as the damaging effects of an unintended pregnancy. In particular, the promotion of resilience in a person needs to be culturally specific. Resilience is a strength-based concept, meaning its focus is on providing support and opportunities which promote life success. Pregnant teenagers who demonstrate risky health behaviors have been found to have significantly negative outcomes during pregnancy [6]. Therefore, resilience can be increased in a universal capacity, and allow pregnant teenagers to prevent and overcome adversities, as well as the damaging effects of adversity.

Encouraging pregnant teenagers to be resilient can overcome the negative effects of adversity and improve their lives. The nurse as a health care provider may play a useful role in encouraging resilience in teenage pregnant women and help them to develop positive outcomes. Teenage pregnant women need to have their resilience enhanced so they develop more competency, including inner strength, external support, and interpersonal and problem solving skills, to manage the several adversities they may face in their lives. The purpose of this study was to test a resilience enhancing intervention delivered by nurses (RENP) during pregnancy that can reduce depression and increase resilience for pregnant teenagers. Therefore, prenatal nurses should provide resilience interventions for pregnant teenagers to help them overcome adversities.

\section{Methods}

Study design: The quasi experimental format was used to test the resilience enhancing nurse program (RENP) intervention. The intervention group received the RENP and regular care, and the control group received only regular care. The hypothesis of this study was that pregnant teenagers who received the RENP would have better outcomes, as measured by improved resilience and decreased depression.

Ethical considerations: Ethical approval was obtained from the Ethical Research Committee, the Faculty of Nursing, Prince of Songkla University, Thailand, and two hospitals participating in the study, before collecting the data.

Sample and setting: A medium effect size was used to determine level of statistical significance at $\alpha 0.05$ and 0.80 power [11]. The sample size was determined to be 64 per group. Accounting for attrition, 234 women were screened and 158 eligible participants were randomized to the intervention group $(\mathrm{n}=$ 84) and control group $(\mathrm{n}=74)$. For final data analysis (Figure 1), there were 64 women in the intervention group available ( 5 cases of withdrawal, 5 cases were lost to follow up in the $4^{\text {th }}$ week, and an additional 8 cases were lost to follow up in the $8^{\text {th }}$ week). Sixty-six women in the control group were available for analysis ( 4 cases were lost to follow up in the $4^{\text {th }}$ week, and an additional 4 cases were lost to follow up in the $8^{\text {th }}$ week). The setting for this study was 2 antenatal care clinics at 2 public hospitals in North-Eastern Thailand. These hospitals provide similar standardized care, which in Thailand is at least 4 prenatal care visits at a general hospital that begins when an adult woman or teenager realizes their pregnancy. In normal cases, routine care for pregnant women is a checkup every month until 28 weeks of gestation, then every 2 weeks over the 28 - 36 weeks of gestation, and every week after 36 weeks of gestational age. Purposive sampling was used to recruit subjects during February 2015 to June 2016 from the antenatal care clinic in the both hospitals. Eligibility criteria included all pregnant teenagers of less than 20 years. A minimized randomization software was used to provide the balance of the potential effect for confounding factors [12]. In order to assure homogeneity between the experimental and control groups, subjects were matched on variables of gestational age, current relationship with partner, type of family, and total income per month. All subjects were matched by using a minimized randomization program to control variables affecting outcome variables. These variables were current relationship with partner, type of family, and total income per month. Thus, this study could decrease the threat to internal validity. 


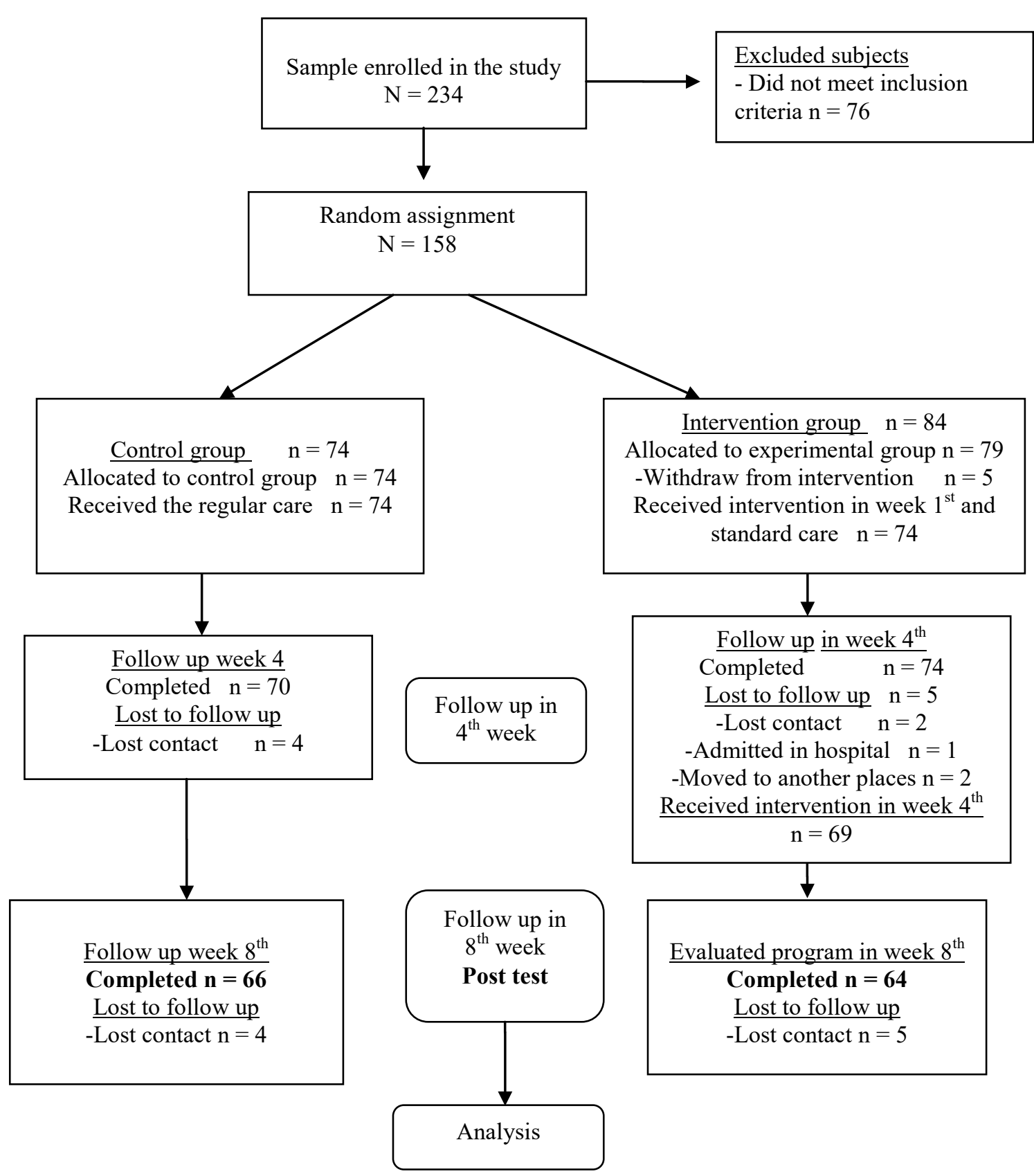

Figure 1 A consort diagram of all subject recruitment and follow up.

\section{Instruments}

The following data was collected at baseline and at 8 weeks post-intervention.

1. The demographic data form was developed by the researcher and used to collect demographic data including age, age of partner/husband, education of teenage pregnant woman, current student status, occupation, total income per month, source of payment for health care service, religion, marital status, 
http://wjst.wu.ac.th

partner's attitude toward having a baby, responsibility of partner, type of family, living arrangements, current relationship with partner/husband, and obstetrical history.

2. The depressive symptoms scale used the CESD-10 depression scale (REF) to measure symptoms of depression in the past week. The scale included 20 items. The Cronbach's coefficient alpha showed 0.90 in this study.

3. Resilience scale was modified from the resilience factors scale for Thai adolescents developed by Takviriyanan [13]. This instrument was developed from the concept of resilience according to Grotberg [14]. The scale included 25 items. The Cronbach's coefficient alpha showed 0.90 in this study.

All instruments were reviewed for content validity by five Thai experts for cultural appropriateness for Thai pregnant women. They were also pilot tested with 30 pregnant teenagers who met the inclusion criteria as subjects in the study. In this study, content validity was tested for the Thai versions of the resilience enhancing nursing program and the handbook guidelines for resilience enhancing. They were examined by 5 experts. The experts were a physician of obstetrics, an APN of midwifery, and 3 nurse instructors who were experts in obstetric nursing, maternal and newborn nursing, and psychiatric nursing. All suggestions from 5 experts were incorporated in the final revision of the questionnaires, program and handbook.

\section{Data collection of procedures}

The researcher encouraged the subjects in each procedure. The procedures of the RENP could be indicated through details including the researcher recruiting subjects for both groups at the antenatal care clinic from 2 hospitals. This study was carried out in antenatal care clinics at both of the hospitals in North-Eastern Thailand. These 2 hospitals provide similar guidelines for standardized care. For routine care in normal cases, pregnant women attended an antenatal clinic unit for a checkup every month until 28 weeks of gestation, then every 2 weeks after the 28 - 36 weeks of gestation, and every week after 36 weeks of gestational age. One hospital had 472 beds for general patients. The hospital antenatal clinic was open from 08:00 - 16:30 h. In 2011 and 2012, there were 146 and 154 cases. The second one had 505 beds for general patients. The antenatal clinic was open from 08:00 - 12:00 h. The hospitals also provided antenatal care supporting the health care policy through an appropriate health care program for teenage pregnant women.

The subjects who met the inclusion criteria were invited to participate in this study. The eligible subjects in this study were divided into 2 groups: the experimental group and control group. There were 64 subjects in each group after the subjects were randomized to the experimental group and control group. The subjects who agreed to participate in the study had to fill in and sign consent forms. The questionnaires for demographic data, resilience scale, and depression scale were administrated to the subjects; they were once again informed of the ethical considerations.

\section{Data analysis}

Descriptive statistics (means, frequencies, standard deviation, and percentages) were used to describe the demographic data. Inferential statistics were used to compare the mean scores of all dependent variables, including depression and resilience within groups. The assumptions of normality and homogeneity of variance of the variable were tested using inferential statistics and checked before the appropriate statistical analysis was performed. Significance was set at a $\mathrm{p}$ value $<0.05$. Paired t-tests were used as tests for the differences of the mean scores within the group comparison, and repeated measures ANOVA was used to test the difference of dependent variables between groups at 3 time points (baseline, 4 weeks, and 8 weeks). 
Table 1 The guidelines of the resilience enhancing nursing program.

\begin{tabular}{|c|c|c|}
\hline \multirow{2}{*}{ Week } & \multirow{2}{*}{ Duration } & Actions \\
\hline & & The Researcher \\
\hline Week 1 & $30 \mathrm{~min}$ & $\begin{array}{l}\text { Establishing trust and relationship } \\
\text { - Providing a private environment } \\
\text { - Encouraging the subject to communicate about her pregnancy and current situation } \\
\text { in order to understand the subject's background and problems during pregnancy } \\
\text { - Developing the relationship and trust through relaxation by starting with turning on } \\
\text { light music, touching and massaging the shoulder, introducing own name to the } \\
\text { group, and sharing experiences regarding their pregnancies }\end{array}$ \\
\hline Week 1 & $30 \mathrm{~min}$ & $\begin{array}{l}\text { Improving resilience; improve inner strength (I am), interpersonal and problem- } \\
\text { solving skills (I can), and external support (I have) } \\
\text { a. Watching VDO clip for inspiration in teenage mothers (I am) } \\
\text { - Providing a VDO clip regarding inspiration for resilience enhancing } \\
\text { - Discussing each of opinion of this clip and the issues involved } \\
\text { b. The tree of resilience (I can) } \\
\text { - Providing an activity for subjects regarding communication in expressing feelings } \\
\text { about pregnancy } \\
\text { - Providing the subject some strategies as follows: self-talk and positive thinking } \\
\text { about confidence and respecting themselves enabling learning and living through } \\
\text { with crisis intervention during pregnancy }\end{array}$ \\
\hline Week 1 & $45-50 \mathrm{~min}$ & $\begin{array}{l}\text { c. The social support during pregnancy (I have) } \\
\text { - Providing a friendly service that is easily accessible and available for consultation } \\
\text { during pregnancy } \\
\text { - Searching for personal support who is trusted the most during pregnancy } \\
\text { - Informing the significance of resilience }\end{array}$ \\
\hline $\begin{array}{c}\text { Week } \\
2,3\end{array}$ & $10-15 \min$ & $\begin{array}{l}\text { Monitoring and encouraging the resilience practice } \\
\text { 1. Asking the subject how they have practiced resilience with the previous week } \\
\text { 2. Providing information regarding procedures from the resilience enhancing } \\
\text { handbook. The subjects will practice as follows: } \\
2.1 \text { Practicing increasing internal strength (I am) } \\
2.2 \text { Practicing positive thinking for problems, self-talk, and assertiveness for } \\
\text { increasing external support (I have) } \\
2.3 \text { Practicing changing a crisis situation in a positive way, considering positive } \\
\text { ways of problem solving, planning and managing problem solving, and finding other } \\
\text { support for increasing interpersonal and problem solving skills (I can) }\end{array}$ \\
\hline Week 4 & 30 in & $\begin{array}{l}\text { 3. Providing the VDO } \\
\text { 4. Conclusion of all outcomes in the activity of pregnant teenagers are encouraged } \\
\text { to share their opinions about their experience }\end{array}$ \\
\hline $\begin{array}{l}\text { Week } \\
5,6,7\end{array}$ & $10-15 \mathrm{~min}$ & $\begin{array}{l}\text { Monitoring and encouraging resilience practice (Follow up by telephone) } \\
\text { - Continuing to practice the resilience enhancing by telephone follow up } \\
\text { - Monitoring practice through self-report of the resilience practice } \\
\text { - Sharing problems and experiences of resilience practice by technology of the social } \\
\text { network to provide in group participant }\end{array}$ \\
\hline Week 8 & & $\begin{array}{l}\text { The evaluation of program } \\
\text { - Giving the research instruments to the subject, including depression scale and } \\
\text { resilience scale }\end{array}$ \\
\hline
\end{tabular}




\section{Results}

\section{Characteristics data of the participants}

The demographic data of participants who were randomly assigned to the experimental $(n=64)$ and control $(n=66)$ groups were as follows. In the experimental group, the mean age was 17.39 years $(\mathrm{SD}=$ $1.83)$, the age of the baby's father was an average of 20.52 years $(\mathrm{SD}=3.51)$, the gestational age at baseline was 19.08 weeks $(\mathrm{SD}=5.52)$, the gestational age of first attending the antenatal care clinic was 13.50 weeks $(\mathrm{SD}=5.01)$, and the period of contraception before pregnancy was 5.26 months $(\mathrm{SD}=8.01)$. The majority of pregnant teenagers in this group had a highest education level of high school or high school graduate $(87.5 \%)$, and worked in a family business or on a farm (57.6\%). Approximately $25 \%$ had quit their current status as a student. However, thirty-four percent of participants were still actively studying in school. The total family income per month of the pregnant teenager and her partner was less than 5,000 baht (73.4\%), and they paid for their own payment of health care through universal coverage during their pregnancy $(100 \%)$. Most of the participants still lived with their partners, and the parent(s) on both sides did not accept their unmarried status $(48.4 \%)$. Other pregnant teenagers $(45.3 \%)$ still lived with their family. The majority of teenagers had partners who accepted the pregnancy and acknowledged the baby was theirs $(89.4 \%)$, had a good current relationship with their partners or husbands $(95 \%)$, and had been given good care from the responsible partner or husband $(92.4 \%)$. There were no complications during pregnancy in the experimental group (96.9\%).

For the control group, the average age was 17.35 years $(\mathrm{SD}=1.70)$, the age of the baby's father was 21.28 years $(\mathrm{SD}=3.93)$, the gestational age was 18.64 weeks $(\mathrm{SD}=6.27)$ at baseline, the gestational age of first attending the antenatal care clinic was 12.67 weeks $(\mathrm{SD}=5.50)$, and the average period of contraception before pregnancy was 3.92 months $(\mathrm{SD}=5.88$ ) (see Table 3 ). The majority in this group had a highest education level of high school / high school graduate $(81.8 \%)$, and worked in a family business or on a farm (43.8\%). Approximately $30 \%$ had quit their current status as a student, while $27 \%$ were still actively studying in school. The majority had a total income per month of the pregnant teenager and her partner of less than 5,000 baht $(65.1 \%)$, and paid for their own health care through universal coverage during their pregnancy $(93.8 \%)$. This group had a higher number of participants living with partners where the parents accepted the unmarried status $(57.6 \%)$. Nearly all of their partners accepted the pregnancy and acknowledged the baby was theirs (100\%). Most of the participants had a good current relationship with their partner or husband $(98.4 \%)$, they had been given good care from the responsible partner or husband $(95.3 \%)$, and there were no complications during pregnancy $(90.9 \%)$.

Using the independent t-test, there were no differences in age, gestational age, gestational age at first attending antenatal care services, or the period of contraception before pregnancy between two groups. Moreover, results of chi-square test showed that there were no differences in education, employment, current status as a student, income, relationship, heath care scheme, marital status, partner's attitude towards the pregnancy, relationship with partner or husband, or responsibility of partner or husband.

\section{Depression}

The depression scores in pregnant teenagers after receiving the resilience enhancing nursing program (RENP) in the experimental group was lower than the control group after receiving the program. In the control group, the mean scores of depressions at base line, $4^{\text {th }}$ week, and $8^{\text {th }}$ week after receiving the program were $16.76(\mathrm{SD}=8.14), 12.74(\mathrm{SD}=5.9)$, and $13.14(\mathrm{SD}=4.84)$. For the experimental group, results show that there was a decrease in depression at the $4^{\text {th }}$ week and $8^{\text {th }}$ week. The mean scores of depression for this group were 17.44 ( $\mathrm{SD}=9.25), 12.92(\mathrm{SD}=6.57)$, and $12.38(\mathrm{SD}=6.02)$. Therefore, the null hypothesis is accepted that there were no significant differences in the decrease of depressive scores between the experimental and control groups at each designated week point (Table 2). 
http://wjst.wu.ac.th

Table 2 Comparison of the depression scores in experimental and control groups classified by time point $(\mathrm{N}=130)$.

\begin{tabular}{|c|c|c|c|c|}
\hline \multirow[t]{2}{*}{ Time point } & $\begin{array}{l}\text { Control group } \\
(\mathrm{n}=66)\end{array}$ & $\begin{array}{l}\text { Experimental group } \\
(\mathrm{n}=64)\end{array}$ & \multirow[t]{2}{*}{$t$} & \multirow[t]{2}{*}{$p$-value } \\
\hline & Mean(SD) & Mean(SD) & & \\
\hline Baseline (T1) & $16.76(8.14)$ & $17.44(9.24)$ & -0.444 & 0.658 \\
\hline $4^{\text {th }}$ week (T2) & $12.74(5.91)$ & $12.92(5.57)$ & -0.164 & 0.870 \\
\hline $8^{\text {th }}$ week (T3) & $13.14(4.84)$ & $12.38(6.02)$ & -0.793 & 0.428 \\
\hline
\end{tabular}

Figure 2 shows the mean scores of depression at each time point between the experimental group and control group. A repeated measure of ANOVA was used to examine the differences in depression scores over time between the experimental group and control groups. There was a significant difference in depression scores by time alone $(\mathrm{F}=14.199, p<0.001)$ (Table 4). These findings may reflect that the resilience enhancing nursing program performed over the $4^{\text {th }}$ week and $8^{\text {th }}$ week was not significantly effective in enhancing resilience in pregnant teenagers. ANOVA (split-plot design) was tested three times to compare depression between the experimental and control groups.

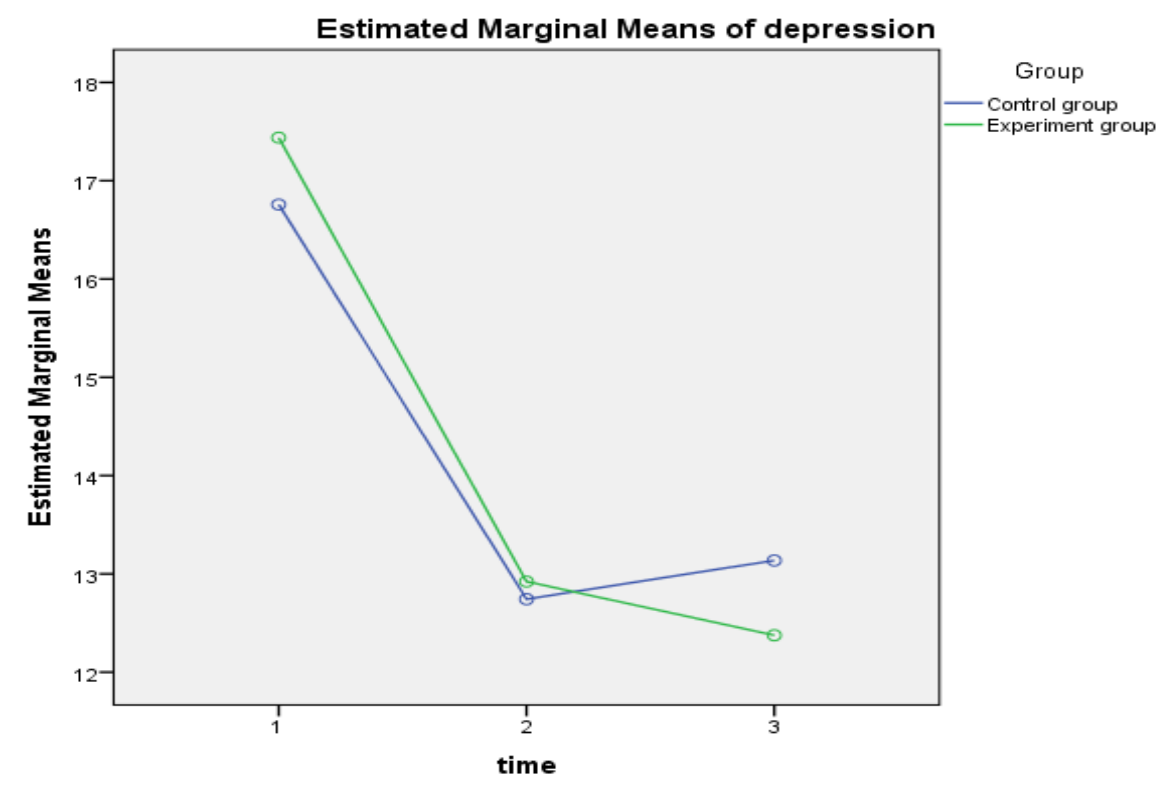

Figure 2 Mean scores of depression between the control and experimental groups at baseline (T 1), $4^{\text {th }}$ week (T 2), and $8^{\text {th }}$ week (T 3).

The repeated measures ANOVA showed a significant difference in depression by time alone from base line (T1), $4^{\text {th }}$ week, (T2), and $8^{\text {th }}$ week $(\mathrm{T} 3)(\mathrm{F}=14.199, p<0.001)$. However, there were no significant differences between interaction of time by group alone in depression $(\mathrm{F}=0.526, p=0.592)$. In 
http://wjst.wu.ac.th

addition, there was no significant difference in depression by group alone $(\mathrm{F}=0.002, p=0.969)$ (Table 3).

Table 3 Analysis of variance for depression in pregnant teenagers at baseline, $4^{\text {th }}$ Week, and $8^{\text {th }}$ Week after receiving the program by time point (test of between and within group) $(\mathrm{N}=130)$.

\begin{tabular}{cccccc}
\hline Source of variation & SS & df & MS & $\boldsymbol{F}$ & $\boldsymbol{p}$-value \\
\hline Between group & & & & & 0.969 \\
Group & 78936.412 & 1 & 78936.412 & 0.002 & 0.001 \\
Error & 8681.252 & 128 & 67.822 & & 0.592 \\
Within group & & & & & 14.199 \\
Time & 1605.168 & 2 & 802.554 & 0.526 & 0 \\
Group*time & 34.798 & 2 & 17.399 & & \\
Error & 9814.622 & 256 & 38.338 & & \\
\hline
\end{tabular}

\section{Resilience}

The resilience scores in pregnant teenagers after receiving the resilience enhancing nursing program (RENP) in the experimental group were higher than the control group after receiving the program. The repeated measures ANOVA showed a significant difference in resilience by time alone from baseline (T1), $4^{\text {th }}$ week, (T2), and $8^{\text {th }}$ week (T3) $(\mathrm{F}=10.523, p<0.001)$. However, there were significant differences between interaction of time by group alone in resilience $(\mathrm{F}=43665.767, p=0.969)$. In addition, there was no significant difference in resilience by group alone $(\mathrm{F}=0.004, p=0.996)$. Participants in the experimental group had a higher improvement in resilience. In particular, there was a significant difference in resilience by group alone $(\mathrm{F}=43665.767, p<0.001)$ (Table 5).

Table 4 Comparison of the resilience scores in experimental and control groups classified by time point $(\mathrm{N}=130)$.

\begin{tabular}{|c|c|c|c|c|}
\hline & $\begin{array}{l}\text { Control group } \\
(\mathrm{n}=66)\end{array}$ & $\begin{array}{l}\text { Experimental group } \\
(\mathrm{n}=64)\end{array}$ & $t$ & $p$-value \\
\hline Time point & Mean(SD) & Mean(SD) & & \\
\hline Baseline (T1) & $74.65(6.42)$ & $76.50(8.12)$ & -1.436 & 0.155 \\
\hline $4^{\text {th }}$ week (T2) & $76.92(3.86)$ & $78.86(3.86)$ & -2.310 & 0.023 \\
\hline $8^{\text {th }}$ week (T3) & $76.86(3.16)$ & $78.70(5.26)$ & -2.421 & 0.017 \\
\hline
\end{tabular}


http://wjst.wu.ac.th

Table 5 Analysis of variance for resilience in pregnant teenagers at baseline, $4^{\text {th }}$ Week, and $8^{\text {th }}$ week after receiving the program (test of between group and within group) $(\mathrm{N}=130)$.

\begin{tabular}{crrrrr}
\hline Source of variation & \multicolumn{1}{c}{ SS } & \multicolumn{1}{c}{$\boldsymbol{d} \boldsymbol{f}$} & \multicolumn{1}{c}{ MS } & $\boldsymbol{F}$ & $\boldsymbol{p}$-value \\
\hline Between group & 342.462 & 1 & 342.426 & 43665.767 & $<0.001$ \\
Group & 6791.336 & 128 & 53.057 & & \\
Error & & & & & \\
Within group & 444.038 & 2 & 222.019 & 10.523 & 0.001 \\
Time & 0.181 & 2 & 0.091 & 0.004 & 0.996 \\
Group*time & 5401.137 & 256 & 21.098 & & \\
Error & & & &
\end{tabular}

Figure 3 shows the mean scores of resilience at each time point between the experimental group and control group. A repeated measure of ANOVA was used to examine the differences in resilience score over time between the experimental group and control groups. There was a significant difference in resilience scores by time alone $(\mathrm{F}=10.523, p<0.001)$ (Table 5). These findings may reflect that the resilience enhancing nursing program performed over the $4^{\text {th }}$ week and $8^{\text {th }}$ week was not significantly effective in enhancing resilience in pregnant teenagers. ANOVA (split-plot design) was tested three times to compare resilience between the experimental and control groups.

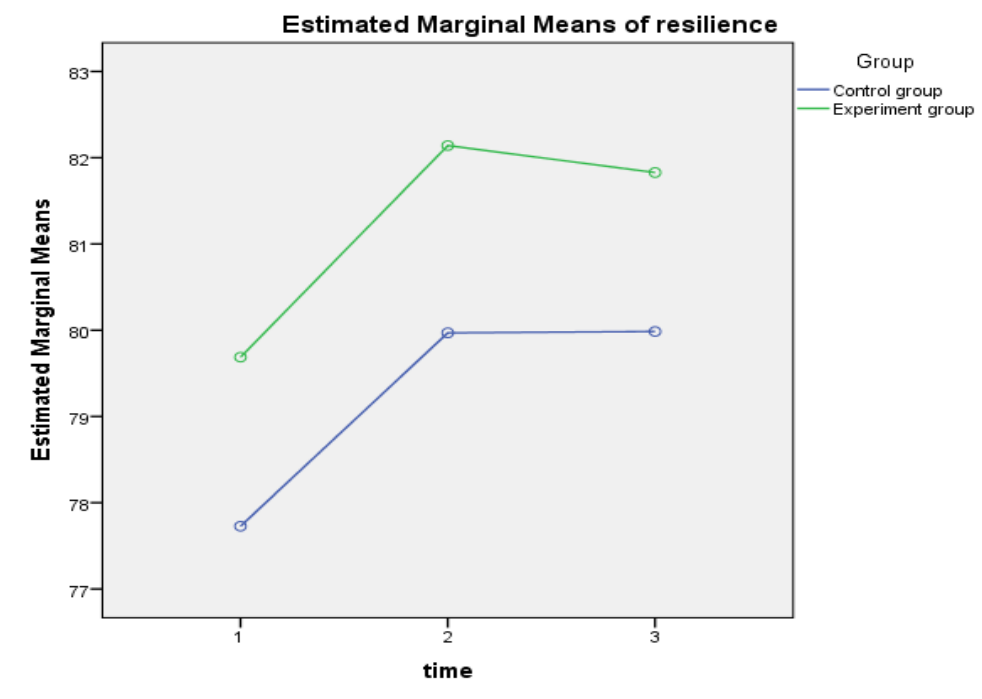

Figure 3 The mean scores of resilience between the control and experimental groups at baseline $(\mathrm{T} 1), 4^{\text {th }}$ week (T 2), and $8^{\text {th }}$ week (T 3 ). 


\section{Discussion}

The results of the study are discussed and compared with several previous studies. The dependent variables of depression and resilience were measured at the $4^{\text {th }}$ week and $8^{\text {th }}$ week post-intervention. The results showed that a decrease in depression scores in the experimental group, and the scores of depression on completion of the program being lower than the baseline, were not supported in this study. According to these results of this study, the program might not immediately reduce depression in the prenatal period in the $4^{\text {th }}$ week. The depression scores decreased at the $4^{\text {th }}$ week and $8^{\text {th }}$ week after receiving the program as compared to before receiving the program. In addition; there was not any significant difference in depression scores among pregnant teenagers who received the program and those who received regular care after completing the program at the $4^{\text {th }}$ week and $8^{\text {th }}$ week of follow up (Table 3).

Depression in pregnant teenagers has serious negative consequences that may impact on the mother and newborn in regards to the aspects of emotional and physical health in the future. Depression is a significant mental disorder that demonstrates as depressed moods and poor emotional levels [7]. Pregnancy during the teenage period of life can often lead to depression in pregnant teenagers compared to adults [15]. The results of this study show a tendency for a decrease in depression scores but this was not significant. A possible explanation for these findings is that most participants had the support of their partners/fathers of the babies, and many also had the support of their parents. The majority of participants lived with their husbands and/or with their families.

Teenage pregnant women who reported that their partners accepted and acknowledged that they were the fathers of the baby had good current relationships, were being given good care from the partners, and neither group had any complications during pregnancy. These results are similar to another study that showed depressive symptoms reduced during the prenatal period [16]; also, the negative consequences of maternal depression can lead to impact on teenage mothers more than older groups $[3,17,18]$. The findings showed no significant differences in decrease of depression scores at baseline, the $4^{\text {th }}$ week, and the $8^{\text {th }}$ week when comparisons were made between groups. In the control group, most parent(s) on both sides accepted the unmarried status much more than parent(s) in experimental group. In this study, it was found that more than $60 \%$ of the samples were unmarried and there were no significant differences in the experimental and control group. Some studies assessing resilience during pregnancy have mainly focused on depressive components using nonspecific instruments [19,20]. For instance, one study measured the level of depression rather than resilience after an ultrasound consultation in uncomplicated gravid with different risks of fetal abnormalities [21]. Promoting resilience has been closely associated with an increase in high self-esteem that will be a protective factor and an outcome to be welcomed in teenage pregnancy [19]. Therefore, to promote resilience in pregnant teenagers can reduce depression during pregnancy and improve good health outcomes for maternity and the newborn.

One study found a significantly greater improvement in resilience that was shown in participants with depressive symptoms who received the program of a self-help manual on promotion of resilience which was maintained for one month of follow up throughout both groups [10]. Another previous study showed reduced depression immediately in the prenatal period in 4 weeks [22]. This is similar to the study of a group antenatal intervention to reduce stress and depressive symptoms during the prenatal period [23]. In addition, similar findings in the effectiveness of the Personal Resilience and Enrichment Program (PREP) were investigated, which showed that promoting resilience can improve psychological outcomes, including depressive symptoms, sense of being, and sense of purpose, which were identified as the same variable outcomes [24]. Congruence with these systematic reviews are indicated by the Penn Resilience Program (PRP) that can promote positive emotions in depressive symptoms in school students [25-27]. Moreover, studies from a meta-analysis revealed the significance of the Peen Resilience Program at 6 - 12 months for all follow up interventions in increasing hope in, decreased depression in, adolescents [29].

This study is congruent with another study following teenage pregnant women, which showed that depressive scores in teenage mothers by ethnicity were significantly different at baseline, but these differences were no longer significant by 3 months postpartum [30]. In contrast, Horowitz and Garber 
http://wjst.wu.ac.th

[22] found higher levels of depression at baseline, and the scores increased over time, in participants who had a basis of risk status and subclinical symptoms. Particularly, during early pregnancy, most pregnant teenagers may feel uncertain about their pregnancy [31], and also some participants in the experimental group moved to another area with their partners or families; this may have impacted on increasing depression [32].

Participants in the experimental group did not show significantly lower levels of depression at the $4^{\text {th }}$ week, as was expected. A booster session of the intervention of the program may be necessary in teenage pregnant woman, as well as the provision of more information, education, and knowledge about newborn care, as suggested in another study [33]. In regards to the sessions of the program, there should be a booster session after 8 weeks until the third trimester gestational age and after delivery at around 6 months. Several studies have looked at resilience that was based on an interview performed at delivery and 8 weeks later after a hurricane experience during pregnancy using the Edinburgh Depression Scale and the Post-Traumatic Stress Checklist as an indirect measure of mental health resilience [34]. Therefore, studies should be focused on the strategies that enhance resilience in pregnant teenagers that should be undertaken by health care professionals in health care services, educationalists, and social workers.

Resilience can promote opportunities for life success and positive outcomes. These may include physical outcomes and psycho-social outcomes. Consequently, resilience can help pregnant teenagers to overcome many adversities during the prenatal period. Therefore, an increasing resilience in pregnant teenagers may help them overcome life adversities and the negative effects of teenage pregnancy. Nurses and other health care providers should provide promote resilience for pregnant teenagers for the well being of both the mothers and their babies.

\section{Conclusions}

The study evaluated the resilience enhancing nursing program on the outcomes of resilience and depression among pregnant teenagers. The intervention was conducted over a one year period, from March 2015 to March 2016. Data from the baseline, $4^{\text {th }}$ week, and $8^{\text {th }}$ week evaluations were analyzed using descriptive statistics, chi-square test, independent t-test, paired t-test, and repeated measures. A final 130 subjects were recruited, with 64 in the experimental group, and 66 in the control group, and randomly assigned to either the experimental or the control group. In all steps of the resilience enhancing nursing program (RENP), the following elements were adhered to; establishing trusting relationships, resilience enhancement, intervention monitoring, and the evaluation of the program. The resilience enhancing nursing program did not result in significantly different mean scores of depression in pregnant teenagers in the experimental group when compared to the control group. There was no significant decrease in depression levels from baseline to the end of program. Therefore, in developing strategies to promote better mental health for teenage pregnant women, we must be concerned with the context of the participants' lives and the resources of support for them. It is likely that, in another group of pregnant women in need of crisis interventions, such as those with a high risk of pregnancy, there would be opportunities suitable for ensuring the effectiveness of the interventions in this particular group.

\section{Limitations}

There was a limited time to collect the data and follow up after participants had entered the program, so there were a large number of participants who dropped out due to follow up and participants withdrawing themselves from the experimental and control groups. Attrition is a longitudinal methodology of randomization in pregnancy and also the postpartum period. In this study, some participants were lost because they moved to another place and did not give forwarding addresses, migrated to the city, did not respond because they were away from their homes, or they did not come to follow up in the evaluation program. Therefore, the researcher should form stronger relationships and have a stronger commitment with the pregnant teenagers in the control and experimental groups. 
http://wjst.wu.ac.th

\section{Recommendations for further study}

This program can be useful to guide practice nurses and counseling nurses who incorporate nursing interventions as a part of their programs to reduce depression for teenage pregnant women of unplanned pregnancy in clinical practice. As a result of serious outcomes, nurses or nurse midwives who are closely associated with pregnant teenagers should be concerned about this potentially risky group for early detection in the prenatal period and provide an effective intervention or an appropriate nursing program. Such nursing interventions need to enhance the resilience of these pregnant teenagers to overcome many adversities which are most important for them to understand during the prenatal period. Further research in other settings using a randomized controlled trial should be replicated to assess the effectiveness of this program in each trimester of gestational age teenage pregnancy and for teenage mothers who are in the postpartum period. Qualitative research approaches are recommended to explore the long term effects of the group program, not only on improving teenage pregnant women and their families. Replication of the study with a larger size and randomly selected participants in another setting and several geographic areas are needed to broaden the generalized study.

\section{Acknowledgements}

This research was supported by the Faculty of Nursing, Mahasarakham University, Thailand, and also the Graduate School, the Prince of Songkla University, Thailand. We would like to thank the staff and participants from Kalasin and Mahasarakham hospitals, Thailand.

\section{References}

[1] Millennium development goals, Progress towards the health-related millennium development goals, Available at: http://www.who.int/mediacentre/factsheets/fs290/en/index.htmlt, accessed September 2013.

[2] SS Luthar, D Cicchetti and B Becker. The construct of resilience: A critical evaluation and guidelines for future work. Child Dev. 2000; 71, 543-62.

[3] C Logan, E Holcombe, J Manlove and S Ryan. The Consequences of Unintended Childbearing: A White Paper. ChildTrends, 2007.

[4] A Pillitteri. Maternal and Child Health Nursing: Care of the Childbearing and Childrearing Family. $6^{\text {th }}$ ed. Lippincott Williams \& Wikins: Wolter Klower, 2010.

[5] P Lumbiganon, M Laopaiboon, AM Gülmezoglu, JP Souza, S Taneepanichskul, P Ruyan, DE Attygalle, N Shrestha, R Mori, ND Hinh, HT Bang, T Rathavy, K Chuyun, K Cheang, M Festin, V Udomprasertgul, MJV Germar, G Yanqiu, M Roy, G Carroli, K Ba-Thike, E Filatova and J Villar. Method of delivery and pregnancy outcomes in Asia: The WHO global survey on maternal and perinatal health 2007-2008. Lancet 2010; 375, 490-9.

[6] A Pillitteri. Maternal and Child Health Nursing: Care of the Childbearing and Childrearing Family. $7^{\text {th }}$ ed. Lippincott Williams \& Wikins: Wolter Klower; 2015.

[7] RS Siegal and AR Brandon. Adolescents, pregnancy, and mental health. J. Pediatr. Adolesc. Gynecol. 2014; 27, 138-50.

[8] WHO. Depression, Avalible at: http://www.who.int/topics/depression/en, accessed April 2014.

[9] RT Mercer and LO Walker. A review of nursing interventions to foster becoming a mother. $J$. Obstetric Gynecol. Neonatal Nurs. 2006; 35, 568-82.

[10] AH Salonen, M Kaunonen, P Åstedt-Kurki, AL Järvenpää, H Isoaho and MT Tarkka. Effectiveness of an internet-based intervention enhancing finnish parents' parenting satisfaction and parenting self-efficacy during the postpartum period. Midwifery 2011; 27, 832-41.

[11] J Cohen. Statistical Power Analysis for the Behavioral Sciences. $2^{\text {nd }}$ ed. Lawrence Erlbaum Associates, New Jersey, 1988.

[12] DL Zeller. The program minimized randomization 2.01. 1997; Available at: http://mahmoodsaghaei.tripod.com/Softwares/randalloc.html, accessed April 2014. 
http://wjst.wu.ac.th

[13] N Takviriyanun. Development and testing of the resilience factors scale for Thai adolescents. Nurs. Health Sci. 2008; 10, 203-8.

[14] EH Grotberg. What is Resilience? How do you Promote It? How Do You Use It? In: EH Grotberg (Ed.). Resilience fo Today: Gaining Strenght From Adversity. Praeger, Westport, CT, 2003, p. 1-30.

[15] SC Hodgkinson, E Colantuoni, D Roberts, L Berg-Cross and HM Belcher. Depressive symptoms and birth outcomes among pregnant teenagers. J. Pediatr. Adolesc. Gynecol. 2010; 23, 16-22.

[16] SSK Leung and TH Lam. Group antenatal intervention to reduce perinatal stress and depressive symptoms related to intergenerational conflicts: A randomized controlled trial. Int. J. Nurs. Stud. 2012; 49, 1391-402.

[17] SA Wolchik, CE Schenck and IN Sandler. Promoting resilience in youth from divorced families: Lessons learned from experimental trials of the new beginnings program. J. Pers. 2009; 77, 183368.

[18] BM Dossey and L Keegan. Holistic Nursing. $5^{\text {th }}$ ed. Jones and Bartlett, Sudbury, MA, 2009.

[19] AM Pidgeon, L Ford and F Klaassen. Evaluating the effectiveness of enhancing resilience in human service professionals using a retreat-based Mindfulness with Metta Training Program: A randomised control trial. Psychol. Health Med. 2014; 19, 355-64.

[20] D Salazar-Pousada, D Arroyo, L Hidalgo, FR Pérez-López and P Chedraui. Depressive symptoms and resilience among pregnant adolescents: A case-control study. Obstet. Gynecol. Int. 2010; 2010, 7.

[21] P Maxson and ML Miranda. Pregnancy intention, demographic differences, and psychosocial health. J. Womens. Health. (Larchmt) 2011; 20, 1215-23.

[22] JL Horowitz and J Garber. The prevention of depressive symptoms in children and adolescents: A meta-analytic review. J. Consult. Clin. Psychol. 2006; $74,401-15$.

[23] LE Ross and CL Dennis. The prevalence of postpartum depression among women with substance use, an abuse history, or chronic illness: A systematic review. J. Womens. Health (Larchmt) 2009; 18, 475-86.

[24] WW Yuen, WC Wong, CS Tang, E Holroyd, AF Tiwari, DY Fong and WY Chin. Evaluating the effectiveness of personal resilience and enrichment programme (PREP) for HIV prevention among female sex workers: A randomised controlled trial. BMC Publ. Health 2013; 13, 683.

[25] JJ Cutuli, JE Gillham, TM Chaplin, KJ Reivich, MP Seligman, RJ Gallop, RM Abenavoli and DR Freres. Preventing adolescents' externalizing and internalizing symptoms: Effects of the Penn Resiliency Program. Int. J. Emot. Educ. 2013; 5, 67-79.

[26] MP Seligman, RM Ernst, JE Gillham, KJ Reivich and M Linkins. Positive education: Positive psychology and classroom interventions. Oxf. Rev. Educ. 2009; 35, 293-311.

[27] JE Gillham, KJ Reivich, DR Freres, TM Chaplin, AJ Shatte, B Samuels, AGL Elkon, S Litzinger, M Lascher, R Gallop and MEP Seligman. School-based prevention of depressive symptoms: A randomized controlled study of the effectiveness and specificity of the Penn Resiliency Program. $J$. Consult. Clin. Psychol. 2007; 75, 9-19.

[28] ME Seligman. Building resilience. Harvard Buss. Rev. 2011; 89, 100-6.

[29] SM Brunwasser, JE Gillham and ES Kim. A meta-analytic review of the Penn Resiliency Program's effect on depressive symptoms. J. Consult. Clin. Psychol. 2009; 77, 1042-54.

[30] W Samankasikorn, B Pierce, AS Ivany, SH Gwon, D Schminkey and L Bullock. Effect of home visiting with pregnant teens on maternal health. MCN. Am. J. Matern. Child Nurs. 2016; 41, 162-7.

[31] V Goyal, S Borrero and EB Schwarz. Unintended pregnancy and contraception among active-duty servicewomen and veterans. Am. J. Obstet. Gynecol. 2012; 26, 463-9.

[32] V Escribe-Aguir, MC Gonzalez-Galarzo, C Barona-Vilar and L Artazcoz. Factors related to depression during pregnancy: Are there gender differences? J. Epidemiol. Commun. Health. 2008; 62, 410-4.

[33] MC Logsdon, DW Davis, R Stikes, R Ratterman, L Ryan and J Myers. Acceptability and initial efficacy of education for teen mothers. MCN. Am. J. Matern. Child Nurs. 2015; 40, 186-92.

[34] E Harville, X Xiong and P Buekens. Disasters and perinatal health: A systematic review. Obstet. Gynecol. Surv. 2010; 65, 713-28. 